\title{
Design process and simulation testing of a shape memory alloy actuated robotic microgripper
}

\author{
H. Llewellyn-Evans ${ }^{1} \cdot$ C. A. Griffiths ${ }^{1} \cdot$ A. A. Fahmy ${ }^{1}$
}

Received: 19 June 2019/Accepted: 16 August 2019/Published online: 3 September 2019

(C) The Author(s) 2019

\begin{abstract}
Microgrippers are commonly used for micromanipulation of micro-objects with dimensions from 1 to $100 \mu \mathrm{m}$ and attain features of reliable accuracy, low cost, wide jaw aperture and variable applied force. This paper studies the design process, simulation, and testing of a microgripper which can manipulate and assemble a platinum resistance temperature probe, made from a $25 \mu \mathrm{m}$ diameter platinum wire, a $20 \mathrm{~mm}$ diameter tinned copper wire, and a printed circuit board type connector. Various microgripper structures and actuator types were researched and reviewed to determine the most suitable design for the required micromanipulation task. Operation tests using SolidWorks and ANSYS software were conducted to test a parallelogram structure with flexible single-notch hinges. The best suited material was found to be Aluminium alloy 7075-T6 as it was capable of producing a large jaw tip displacement of $0.7 \mathrm{~mm}$ without exceeding its tensile yield strength limit. A shape memory alloy was chosen as a choice of actuator to close the microgripper jaws. To ensure a repeatably accurate datum point, the final microgripper consisted of a fixed arm and a flexible arm. An optimisation process using ANSYS studied the hinge thickness and radius dimensions of the microgripper which improved its deflection whilst reducing the experienced stress.
\end{abstract}

\section{Introduction}

In recent decades, demands for micromanipulation have increased in industrial and commercial application fields due to the nature of technology progressing towards micro and nano-scales. Micromanipulation is the study of positioning micro-objects ranging from 1 to $100 \mu \mathrm{m}$; these micro-sizes can be a challenge to manoeuvre without use of micromanipulator tools due to additional attractive forces, viewing difficulties, high precision, and accuracy requirements (Adriaens et al. 2000; Yuan et al. 2015; Chu Duc et al. 2006). There are two major techniques used for micromanipulation known as contact and non-contact methods, examples of these technologies are electromagnetic fields, piezoelectric materials, electrostatic forces, electrothermal effect, shape memory alloys, magnetic guiding systems, and optical technologies (Nikoobin and Hassani Niaki 2012). These technologies can be utilised in the form of probes, needles, grippers, and contactless

C. A. Griffiths

c.a.griffiths@swansea.ac.uk

1 College of Engineering, Swansea University, Swansea SA2 8PP, UK devices. All of these methods have various advantages and disadvantages, while all are at different stages of continuous development within research community. The aim of this research was to design and develop a micromanipulation tool capable of assembling elements of a resistance temperature detector consisting of a $25 \mu \mathrm{m}$ diameter platinum wire, a $0.2 \mathrm{~mm}$ diameter copper wire, and a printed circuit board (PCB) connector with dimensions $(2.7 \mathrm{~mm} \times 8.5 \mathrm{~mm} \times 0.3 \mathrm{~mm})$. These products are traditionally assembled manually by an operator, however due to the small diameter of the platinum wire they are often difficult to see with the human eye and difficult to handle. Additionally, the positioning of the platinum wire requires a high degree of accuracy and repeatability which is a challenging task for an operator. The combination of these factors suggests that developing a robotic automated system capable of assembling this product would greatly improve the standard of quality of the product and more importantly reduce production cost.

Due to the small nature of the components, robotic controlled micromanipulation tools, such as microgrippers, could be employed to achieve the high level of accuracy and repeatability required. Different micromanipulation tools have been researched, comparing the 
advantages and disadvantages of differing structures and actuator types, for determining the most suitable design for the required micromanipulation task. Robotic tools developed for the medical industry contain state-of-the-art technology, however they may not be suitable for this specific micromanipulation task due to the comparatively large scale of the objects that they are designed to grasp. Another manipulation technology that was studied utilized magnetic fields in order to orientate magnetic or magnetic-tipped wires (Chun et al. 2007). This form of technology is useful for guiding a wire through an intended path, although the system itself could not change the position of the object and only align it with the magnetic field force, therefore would not be suitable for positioning the platinum microwire in the required application. The shape of the microwire also makes it more difficult to manipulate whilst using these technologies. Additionally, many microgrippers are found to be inaccurate, often due to the fabrication process which cause an undesired asymmetrical structure of the microgripper (Liang et al. 2018). For microgripper actuator types, shape memory alloys (SMA) actuated microgrippers previously developed have displayed large jaw displacement and high gripping force compared to other types (Kyung et al. 2008). The SMA disadvantages are high hysteresis error, large energy usage, and a slow response time were found to not greatly impact the manipulation process of the given task (Yang and $\mathrm{Xu}$ 2017). Previous research has not identified a suitable microgripper design that would be capable of grasping and positioning a micro-sized object such as a micro-wire and larger sized objects as well. A solution to this issue has been previously presented while utilizing piezoelectric materials as a form of actuator (Liang et al. 2018), however, this method has not been accomplished using an SMA actuator.

In this research the design of a microgripper that ensure grasping a large range of objects from the sizes of micro-wire to the printed circuit connector board is developed. In Sect. 2 a microgripper design procedure will be followed to identify the optimum forces, environment, actuator settings, microgripper body design, and body material. This is followed in Sect. 3 with a finite element analysis (FEA) of the microgripper structure using the simulation software ANSYS 19.2. The main elements studied using FEA are the jaw displacement $\left(D_{\text {out }}\right)$, stress, and thermal conductivity of the microgripper model. Finally, design refinement of the microgripper body is conducted using a screening optimisation method and a multiple-objective optimisation process to identify the best gripper operations and conclusions are made on the final design specifications.

\section{Gripper design}

\subsection{Gripper tasks}

The process of the microgripper development utilised the design process flowchart proposed by Nikoobin and Hassani Niaki (2012). The method illustrates the recommended steps to successfully design and develop a microgripper for a specific task. The process begins by stating the dimensions and specifications of the object to be manipulated. This involves defining the shape and properties of the object required to be grasped. For this research the objects intended to be grasped include a platinum wire, a connector wire, and a connector board. The platinum wires are made from pure platinum and will be presented to the gripper in the form of a tightly wound coil with two straight tail sections at each end of the wire. It is the straight tail ends of the wire that will be grasped. The diameter of the platinum wire is $25 \mu \mathrm{m}$. The material of the connector wire is tinned copper and will be presented as a straight piece of wire approximately $4 \mathrm{~mm}$ long. The diameter of the connector wire is $0.2 \mathrm{~mm}$. The structure of the connector board is comprised of high-performance epoxy resin with an additional layer of electrical grade glass fabric applied on top. Two parallel tracks of silver are placed on the surface of the connection board for the purpose of soldering the platinum wire and connector wire. After defining the dimensions above, it was concluded that the maximum jaw aperture needed was $0.7 \mathrm{~mm}$. This will ensure that sufficient space will be available in order to grasp the largest object, the connector board. The shapes and dimensions of these objects also effect the ideal jaw shape of the microgripper. Due to the variety of shapes and sizes of the parts a microgripper with flat jaw tips is selected due to its capability of applying sufficient angular pressure to all of the three object types (Kyung et al. 2008).

\subsection{Gripping force on objects}

Correct gripping of the object is a prerequisite for this microgripper design, therefore the force required to apply on the object must be calculated. Insufficient force will result in the object being unintentionally released whereas excess force may damage the object. The minimum force to ensure a firm grasp on the object $\left(F_{\text {out }(\text { grip })}\right)$ was calculated using equations and data used by Festo (2006). When calculating $\left(F_{\text {out }(\text { grip })}\right)$, the maximum acceleration of the system needs to be considered. In this situation, this would be where the microgripper is attempting to manoeuvre the object vertically. The acceleration due to gravity needs to be included in the calculation in addition to the acceleration of the system. 
$F_{\text {out }(\text { grip })}=\operatorname{Sm}(g+a)$

where $F_{\text {out }(\text { grip })}$ is the minimum force, $S$ is the gripping safety factor, $m$ is the mass of the object, $g$ is the gravitational acceleration, and $a$ is the acceleration of the gripper. The forces required for the system will be studied in a subsequent section.

\subsection{Gripper environment}

The next element of the gripper design to consider was the environmental conditions required for the assembly. The area must be dry and clean from foreign particles, such as debris and dust. The assembly process must also be performed on an airbed to ensure a consistent temperature. This is particularly important as the platinum wire has its properties change drastically with a small change in temperature, specifically its resistance which is to be measured throughout the assembly operation.

\subsection{Gripper actuator}

Actuator types such as; SMA, thermal, electromagnetic, electrostatic, and piezoelectric actuators all have numerous advantages and disadvantages. Heat produced by the actuator must be considered as the platinum wire is highly susceptibility to change resistance with a change in temperature, therefore the microgripper jaw must produce minimum heat whilst handling the object. Electrothermal actuators rely on reaching high temperatures, often in excess of $220{ }^{\circ} \mathrm{C}$ to achieve suitable displacement values, hence this technology type was determined as unsuitable for this target (Kolahdoozan et al. 2017). Furthermore, electromagnetic actuators were not preferable since this actuator type is difficult to scale down to small dimensions and may have difficulties with securely grasping the $25 \mu \mathrm{m}$ platinum wire. The piezoelectric type of actuators have high potential to be a suitable choice for this project since a very little heat is produced whilst actuating the system. However, it was concluded that this technology is not capable of achieving the high displacements required to grasp all three intended object sizes. Electrostatic actuators was avoided due to their limited displacement values. One of the designs researched used SMA bimorph strips, which, when heated, would flex and result in closing the jaw and grasping the object (Kolahdoozan et al. 2017). However, due to the cantilever structure, the jaw tips do not remain parallel during operation and thus was considered not suitable for this project.

Shape memory alloy (SMA) wire was chosen as a suitable actuator type for this study. By applying heat to SMA wire, the material will transfer from the martensite stage to the austenite stage which can result in a reduction in length by up to $10 \%$. By utilizing this functionality, it can be applied to manufacture a microgripper structure to produce micro-closure of the jaws. This type of actuator was chosen due to its capabilities of producing a high jaw tip displacement whilst producing high gripping forces to the object to be grasped. A review of microgrippers identified a few structures utilizing SMA wires that are capable of achieving jaw tip displacements around 61-123 $\mu \mathrm{m}$ (Kyung et al. 2008; Munasinghe et al. 2016). Additionally, two other structures, one using SMA wire and the other using SMA bi-metallic strips, were able to reach a large displacements of $5500 \mu \mathrm{m}$ and $7100 \mu \mathrm{m}$, respectively (Lin et al. 2009). The forces applied by the tips of these structures varied between 42.9 and $500 \mathrm{mN}$. However, SMA technology has its own limitations such as, a high hysteresis error, large energy usage, and slow response times. With regard to this specific application, these downfalls are not of concern. As long as the movements of the microgripper jaw are predictable; the hysteresis error will not be considered as an issue. Additionally, the rate of which the jaws open and close are not necessary to monitor as this can be counteracted by allowing sufficient time for the jaws to operate. The large energy usage of the SMA wire is not preferable as it will decrease the energy efficiency of the system. To minimise the impact of this, the system is designed to ensure that the microgripper's jaw are normally open and hence, will only require the actuators to be powered to close the jaws for a short period of time whilst manipulating the objects. The slow response time of the system may be advantageous in this scenario as it will ensure that sudden movements of the jaws do not cause the objects to move whilst attempting to grasp them. However, the SMA wires are actuated by conducting a current through the wire and consequently causing it to increase in temperature. These temperature values are often required to reach $80{ }^{\circ} \mathrm{C}$ to operate. The associated heat may conduct through the microgripper structure if connected directly to the gripper surface. Subsequently, as the temperature of the jaw tips increases, this also increases the temperature of the platinum wire ultimately affecting the platinum wires' resistance. Additionally, the current flowing through the SMA wire would also be capable of flowing through the conductive body of the microgripper. To overcome this, electrically and thermally insulating materials, such as silicon will be studied for the purpose not only to secure the SMA wire to the microgripper structure, but also to reduce the amount of heat conducted to the structure. The SMA wire to be studied is the Flexinol $^{\circledR}$ wire supplied by Dynalloy, INC (2013). The SMA supplied wires are available in various diameters ranging from 0.025 to $0.51 \mathrm{~mm}$. The pulling force that the SMA wire is capable of applying during its contraction (austenite phase), and the force needed to re-stretch the wire is dependent on the 
cross sectional-area of the SMA wire. It has been stated that the larger the diameter of the wire, the greater the force capable of being applied (Zhong and Yeong 2006). When heated, SMA wires are capable of contracting up to a maximum of $10 \%$ of its length. This contraction percentage, also called strain, is partly determined by the force applied to re-stretch the wire during the austenite phase. It is stated on the supplied datasheet by Dynalloy that a restoration biasing force is required to re-stretch the SMA wire to its original length during the martensite stage. If a restoration pressure of $34.5 \mathrm{MPa}$ is applied during cooling then a memory strain of the SMA wire of $3 \%$ can be achieved. If a pressure of $69 \mathrm{MPa}$ is applied, then $4 \%$ can be achieved, and finally if $103 \mathrm{MPa}$ is applied nearly $5 \%$ strain can be achieved. However, increasing the strain towards its maximum limit may reduce the life time use of the wire. This biasing force used to restore the wire will be supplied by the elastic potential energy stored within the structure of the microgripper body. The SMA wires being employed to actuate the microgripper are capable of reducing their length by means of heating, this is the force used to pull together the microgripper jaws. However, SMA wires are not capable of applying a reversing force required to open the jaws to its original position. A solution to overcome this limitation is to utilize the elastic properties of the microgripper structure material that will cause the jaws to re-open to the original position. Therefore the main focus of the research will be to investigate the structure of microgripper body to ensure a normally open jaw configuration capable of closing for short durations.

\subsection{Microgripper design}

The final closing position and the location of the object are required to be highly accurate. The closed jaws need to meet at a predictable central point to avoid inaccuracies during assembly. To control symmetry errors, a microgripper design with one fixed arm and one flexible arm will be studied. This one degree of freedom structure ensures that the jaw tip of the fixed arm will become a rigid datum point and thus be a constant reference throughout the gripping process, irrespective of the type or size of the object being gripped. Each arm of the microgripper comprises a flat jaw tip that should remain parallel to each other during the gripping process. Several designs of microgripper structures and various combinations of actuator types have been studied and developed. For the test piece in this research, the most appropriate style from literature is the parallelogram structure (Fig. 1). This design includes flexible circular single-notch hinges to produce the deformation displacement values required (Long et al. 2017; Wang et al. 2013, 2015; Nah and Zhong 2007; Shi et al. 2018). The benefits of the use of the circular notch hinge include ensuring parallel movement of the microgripper jaws and a precise rotation around the axis. The use of the four hinges, along with two parallel arms, constructs a parallelogram formation, ensuring that the movement of the microgripper jaw remains parallel throughout the gripping operation. These design can also be scaled in size to meet the requirements needed to manipulate a $25 \mu \mathrm{m}$ diameter wire. Figure 1 show the design where $F_{\text {in }}$ is the value of applied force at the input point, $d$ is the distance that the input point is situated along the microgripper arm from the base, $D_{i n}$ is the value of displacement that the input point moves, $l$ is the total length of the flexible section of the arm, $F_{\text {out }}$ is the output force the microgripper jaw is capable of applying, and $D_{\text {out }}$ is the output displacement that the jaw tip moves. At the hinge section values $R$ and $t$ denote the radius of each hinge and the thickness of the hinge wall respectively.

The fixed arm is identified as the passive section and the flexible arm on the right side is the active region. The figure shows the four ideal hinges that provide the flexible arm of the body with two parallel rigid beams connected between them. An approximate displacement of the jaw tip of the microgripper can be calculated using the equation below (Long et al. 2017; Wang et al. 2013).

$D_{\text {out }} \approx D_{\text {in }} \times \frac{l}{d}$

Equation 2 above can be re-arranged to produce the amplification factor, $A$ for the arm as presented in Eq. 3.

$A \approx \frac{D_{\text {out }}}{D_{\text {in }}} \approx \frac{l}{d}$

Therefore, to maximise the displacement amplification factor for the system, the length of $d$ should be a minimum fraction compared to the length. This will cause the displacement of the jaw tip to reach a larger maximum value. However, a large displacement amplification value will result in a reduced force applied by the jaw tip as shown in Eq. 4 (Long et al. 2017).

$F_{\text {out }} \times l \approx F_{\text {in }} \times d$

If the value of the maximum input force is assumed to be constant and the displacement amplification factor is increased, this will cause its inverse value to subsequently decrease and the value of the output force to also decrease as presented in Eq. 5.

$F_{\text {out }} \approx F_{\text {in }} \times \frac{d}{l}$

To reach sufficient values of both output force and output displacement, an optimum value for the amplification factor is required. The pseudo rigid body model is a method used to model compliant mechanisms and follows 
Fig. 1 Gripper design displaying the structure of the microgripper body along with relevant input and output variables

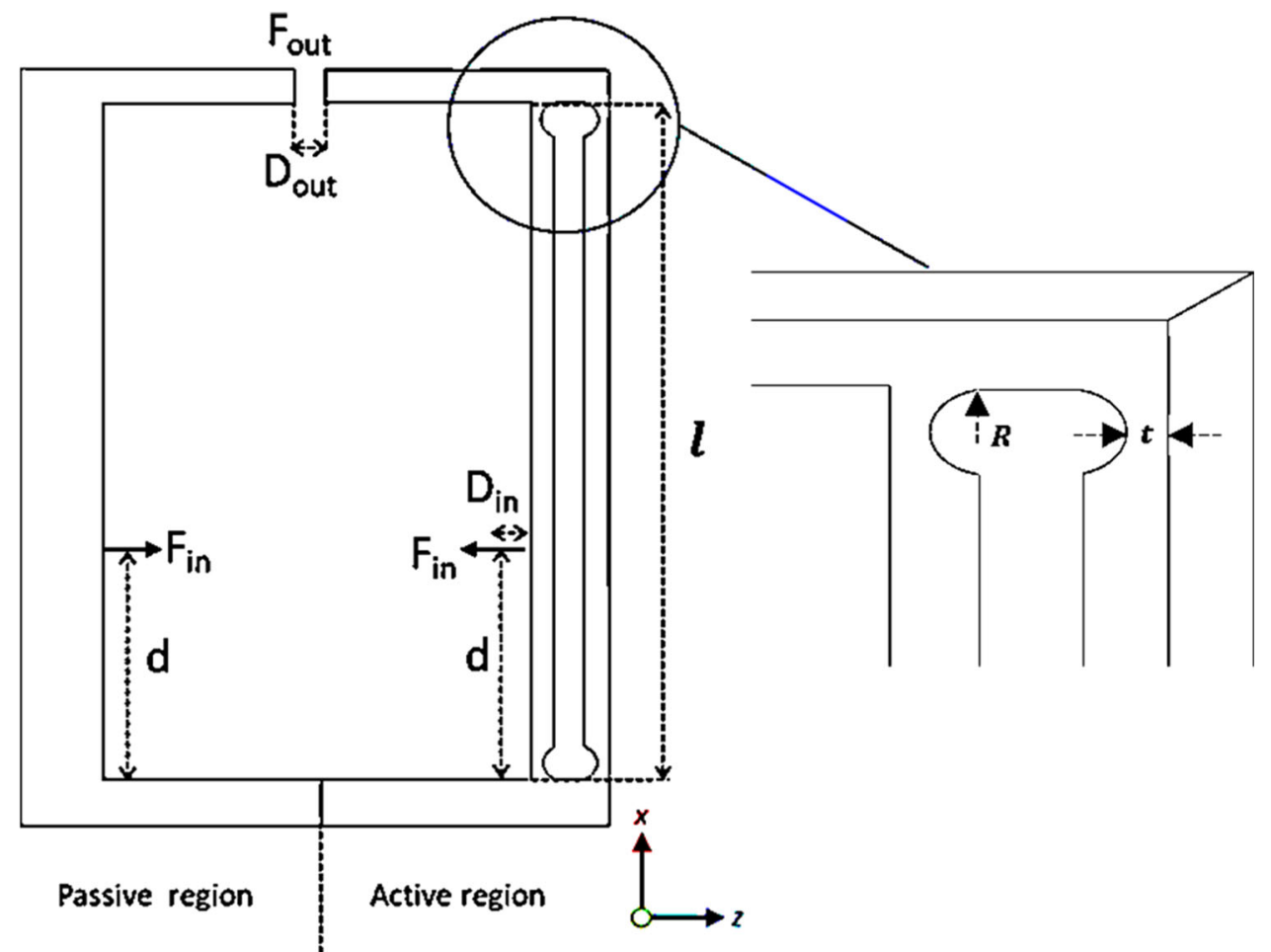

the model of a fixed-guided beam as described by Howell et al. (2013) (Fig. 2) where each flexible hinge is modelled as a torsional spring. Using this method, the microgripper structure design is comprised of revolute joints and rigid beams. In this design, the fixed beams are used to amplify the displacement of the microgripper and the flexible hinges deform during operation and cause the structure to flex. It is the torsion spring that represents the elastic potential of

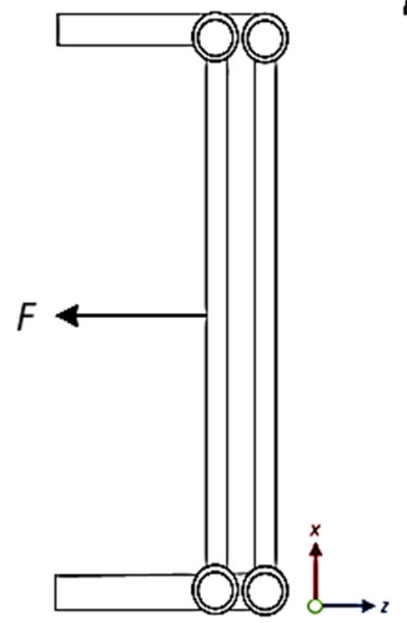

(a)

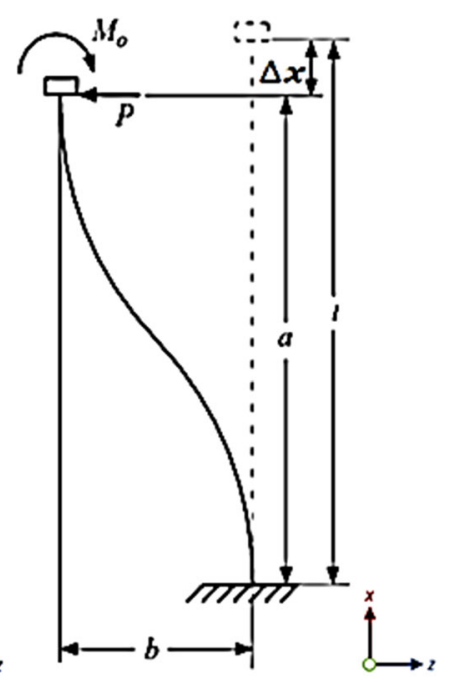

(b)
Fig. 2 a Schematic of the microgripper's flexible arm as defined as a Pseudo rigid body model. b The fixed guided beam as presented by Howell et al. (2013 the system, denoting how the microgripper is capable of restoring to its original position.

To approximate the change in displacement along the zaxis, the equation below is used (Howell et al. 2013).

$b \approx \gamma l \sin \Theta$

where $b$ is the displacement along the z-axis, $l$ is the original length of the microgripper beam between the two flexible hinges, and $\Theta$ is the change in angle between the original position of the flexible hinge and its new deformed position. Finally, $\gamma$ is the characteristic radius factor for the system which can be approximated as 0.85 (Howell et al. 2013).

Since the required displacement in the z-axis has already been presented previously as $0.7 \mathrm{~mm}$, Eq. 6 has been rearranged to find the change in angle between the original position of the flexible hinge and the deformed position as follows.

$\Theta \approx \sin ^{-1}\left[\frac{b}{\lambda l}\right]$

where $b$ has been defined as the value of $D_{\text {out }}$. Using values of $b=0.7 \mathrm{~mm}, l=30 \mathrm{~mm}$, and $\lambda=0.85$, a change in angle is calculated as $1.57^{\circ}$. By utilizing the value calculated from this equation, it is then possible to calculate the value of stress that will be experienced by each hinge under the presented conditions. This is an essential stage of the design process to calculate whether the deformation of the structure will result in the chosen material to reach or 
exceed its elastic limit, subsequently permanently deforming the structure. Equation 8 below can be used for this calculation purpose (Smith and Chetwynd 2005).

$\sigma=\frac{6 \Theta E \sqrt{t} K_{t}}{9 \pi \sqrt{R}}$

where $E$ is the young's modulus of the material and $K_{t}$ is the stress concentration factor of the structure which can be found using Eq. 9 (Smith and Chetwynd 2005).

$K_{t}=\frac{2.7 t+5.4 R}{8 R+t}+0.325$

The displacement along the $\mathrm{x}$-axis of the moving flexible hinge, defined as $\Delta x$, can be calculated using the change in the angle as illustrated in the equations below (Howell et al. 2013).

$\Delta x=l-a=l-\{l[1-\gamma(1-\cos \Theta)]\}$

$\Delta x=|\gamma l(\cos \Theta-1)|$

where $a$ is defined as the x-axis length of arm after deformation.

Hence, using this final equation, a displacement change in the $\mathrm{x}$-axis of approximately $8 \mu \mathrm{m}$ can be obtained. This value is approximately a third of the diameter of the platinum wire to be grasped. With regards to the structure of the microgripper, this value will not be of concern as long as the width of the microgripper jaw tip is larger than the diameter of the platinum wire and that the wire is grasped close to the centre points of each jaw. Each of the hinge structures exhibits a certain stiffness due to its dimensions and the metallurgical properties of the fabrication material. The equation below defines the stiffness of each hinge, $k$ (Royson et al. 2015).

$k=\frac{\sqrt{2} E w t^{\frac{5}{2}}}{9 \pi \sqrt{R}}$

where $E$ defines the Young's modulus of the material, $w$ is the structure width in the y-axis, $t$ is the thickness of the minimum dimension of the hinge bridge in the z-axis, and $R$ is the radius of the hinge.

Given that the Young's modulus remains relatively constant due to the choice of material, the stiffness of the hinge will be dependent on the radius, width, and thickness of the structure. The stress safety factor of the system is also important to establish, and can be calculated using Eq. 13 (Xiao et al. 2011). A stress safety factor greater than 1 is required to ensure that the material of the microgripper does not exceed its elastic limit. Furthermore, the higher the value of the stress safety factor, the greater the number of repetitions the structure can incur without failure.
$S=\frac{\sigma_{y l}}{\sigma}$

where $\mathrm{S}$ is the stress safety factor of the material, $\sigma_{y l}$ is the tensile yield limit of the chosen fabrication material, and $\sigma$ is the stress experienced by the structure.

Based on the pseudo rigid body model calculations, the following variables are established for the initial design of the gripper.

\subsection{Gripper material}

The choice of material for the structure of the microgripper was an essential component to be considered. Various materials have been previously researched for utilising monolithic structures. To achieve a high displacement value for the microgripper, the Young's modulus of the chosen material must be low as this value forms a low stiffness of the material and hence, a high physical flexibility of the structure can be obtained. However, to ensure that damage to the structure does not occur and to increase the lifetime of the tool, the tensile yield limit must be high to ensure that the stress of the structure does not exceed the elastic limit. Overall, an optimum choice of material would have a low young's modulus and a high tensile yield limit. Several different materials have been studied for this purpose which are presented in Table 2 below.

Silicon and silicon dioxide have often been utilized in the development of microgripper structures (Gaafar and Zarog 2017; Chen et al. 2009). It is capable of achieving large displacement with an applied force. However, the fabrication of this material includes photolithography and the process is often complex and expensive and generally used at micro-machine scale, whereas the microgripper fabricated for this project will be in the macro scale (Chronis et al. 2005). Titanium alloys, such as Ti-6AI-4V, has also been recommended for the use of a microgripper structure since it has extremely high strength with a tensile yield strength of $790 \mathrm{MPa}$ (Wang et al. 2013; ASM International 1990). Its value of tensile yield strength indicates that high force values would be required to plastically deform the structure. However, the young's modulus of the material is $113.8 \mathrm{GPa}$, which suggests that a high force would be required to actuate the displacement. Stainless steel alloys, such as 316 , has previously been recommended throughout literature as a choice to fabricate microgripper (Nikoobin and Hassani Niaki 2012; Kyung et al. 2008).

Compared to the other considered materials, stainless steel alloy has the lowest value of tensile yield strength and the highest value of young's modulus. This could lead to a gripper material that would resist deformation, and be more likely to suffer from permanent plastic deformation at the 
lowest stress values. Aluminium alloys have been used alongside several styles of actuators (Liang et al. 2018; Wang et al. 2015; Xu 2018). The aluminium alloy 7075-T6 was specifically suggested by Zubir et al. (2009) for its' capabilities of achieving high displacement values and sustaining high stress levels (Zubir et al. 2009). However, the thermal conductivity of this material is approximately ten times higher compared to the other metals whilst its electrical resistivity is substantially lower than the other metals studied. This is disadvantageous as it would be capable of conducting the electrical current and heat from the SMA wire to the objects being manipulated. Developing the structure out of this material would greatly increase the importance of using an insulating material to prevent these occurrences. Despite the negative properties of the aluminium alloy 7075-T6, it seems the most suitable choice of material to achieve the required conditions of the project.

Using the initial design dimensions of the microgripper (Table 1) and the material characteristics (Table 2), the stiffness $(k)$ of each hinge can be calculated using Eq. 12. When fabricating the hinges using the metal alloys aluminium 7075-T6, stainless steel 316 and titanium Ti-6AI$4 \mathrm{~V}$, the $k$ of each hinge in the structure was $64.15 \mathrm{mNm}^{-1}$, $172.7 \mathrm{mNm}^{-1}$ and $102 \mathrm{mNm}^{-1}$ respectively.

Using Eq. 7, the approximate angle of deflection can be calculated using the values $b=0.7 \mathrm{~mm}, l=30 \mathrm{~mm}$, and $\lambda=0.85$. The deflection angle was found to be $1.57^{\circ}$. This value can then be substituted into Eq. 8 to find the value of the maximum allowable stress of each hinge, $\sigma$. Along with using the values in Table 1 and the value of $E$ for each material, the value of $\sigma$ can be calculated as $195.7 \mathrm{MPa}$, 526.7 $\mathrm{MPa}$ and $310.5 \mathrm{MPa}$ for the alloys of aluminium, stainless steel, and titanium respectively. Comparing these values to each material's tensile yield stress, the aluminium and titanium alloys would not reach half of their maximum limit, resulting in a successful deflection process. However, the stainless steel alloy would exceed its elastic limit and subsequently fail plastically before reaching the full deflection required.

Table 1 Microgripper initial dimensions for actuation

\begin{tabular}{lll}
\hline Variable name and symbol & & Value $(\mathrm{mm})$ \\
\hline Body width & $w$ & 1 \\
Hinge thickness & $t$ & 0.2 \\
Radius of hinge & $R$ & 1 \\
Total length of microgripper arm & $l$ & 30 \\
Position of SMA wire up the arm & $d$ & 15 \\
Displacement of input & $D_{\text {in }}$ & 0.35 \\
\hline
\end{tabular}

\subsection{System forces}

Four different forces must be studied for this investigation. The first being the minimum output force required to grip each object $\left(F_{\text {out }(\text { grip })}\right)$ as previously mentioned. The second is the maximum force that the SMA wire is capable of applying to the input point, this is defined as $F_{\text {in }(S M A)}$. The remaining two values are components of $F_{\text {in }(S M A)}$. Where the first is $F_{\text {in (grip) }}$ is the value of input force required to ensure that output force from the jaw tip is sufficient enough to grip each object. Finally, $F_{\text {in(Jaw) }}$, which is the remaining force available to apply to the input point to close the jaw tip of the microgripper. Each of these will be further studied in detail.

When calculating the value of $\left(F_{\text {out }(\text { grip })}\right)$, Eq. 5 can be used and therefore the variables in the equation must be identified. The average acceleration value for industrial style robotic manipulators is stated to be around $4 \mathrm{~ms}^{-2}$ (Dumetz et al. 2006). A gripping safety factor of 2 was introduced to ensure any error or possible real-world variables were eradicated (Xiao et al. 2011).

The mass of the platinum wire was calculated theoretically using its volume and density. The wire diameter has been previously stated as $25 \mu \mathrm{m}$ and has an average length of $30 \mathrm{~cm}$ resulting in a total volume of $1.46 \mathrm{~mm}^{3}$. The density of commercial grade platinum has a value of $21.45 \mathrm{~g} / \mathrm{cm}^{3}$ (ASM International 1990). Hence, the mass of the platinum wire was found to be $3.16 \mathrm{mg}$. This value is the theoretical mass of the wire where the wire was classified as a specific point. Subsequently, the minimum gripping force required was calculated as $87 \mathrm{mN}$. The same process was used to calculate the mass of the connector wire, with the diameter of the wire typically being $2 \mathrm{~mm}$ and a length of $80 \mathrm{~mm}$, the volume of the wire can be calculated to be $2.51 \mathrm{~mm}^{3}$ and the density of the wire as $8.89 \mathrm{~g} / \mathrm{cm}^{3}$ (ASTM International 1994), resulting in a mass of $2.25 \mathrm{mg}$ and a minimum gripping force of $62 \mathrm{mN}$.

Finally, the PCB connector has a length of $8.5 \mathrm{~mm}$ $( \pm 1)$, width of $2.7 \mathrm{~mm}( \pm 0.1)$ and a thickness of $0.3 \mathrm{~mm}$ ( \pm 0.1 ), hence the volume of the board is calculated to be $96.3 \mathrm{~mm}^{3}$ and the density is stated as $2.55 \mathrm{~g} / \mathrm{cm}^{3}$. Using these values, the mass was found to be $24.6 \mathrm{mg}$ with a required gripping force of $678 \mathrm{mN}$. The value of the minimum applied force must be able to successfully and appropriately grip all of these objects. It was deemed that it would not be necessary to calculate a maximum gripping force as the applied force of this magnitude would be near impossible to achieve at this scale.

Actuation of the gripper is done via SMA wire, a selection of the wires available from Dynalloy (2013), consist of diameters $0.038 \mathrm{~mm}, 0.05 \mathrm{~mm}, 0.076 \mathrm{~mm}$, $0.1 \mathrm{~mm}, 0.13 \mathrm{~mm}$. The maximum pulling force, $F_{i n(S M A)}$, is 
Table 2 The various choices of materials with their material properties (Lin et al. 2009; Zhong and Yeong 2006; Chronis et al. 2005)

\begin{tabular}{lllll}
\hline Material properties & \multicolumn{2}{l}{ Material choices } & & \\
\cline { 2 - 5 } & Alu7075-T6 & Stainless steel 316, annealed sheet & Ti-6AI-4V (grade 23) aka TC4 & Sio 2 \\
\hline Density $\left(\mathrm{g} / \mathrm{cm}^{3}\right)$ & 2.81 & 8 & 4.43 & 2.2 \\
Young's modulus $(\mathrm{GPa})$ & 71.7 & 193 & 113.8 & 70 \\
Poission's ratio & 0.33 & 0.265 & 0.342 & 0.17 \\
Tensile yield strength $(\mathrm{MPa})$ & 434 & 290 & 790 & 155 \\
Tensile ultimate strength $(\mathrm{MPa})$ & 572 & 580 & 860 & 155 \\
Thermal conductivity $\left(\mathrm{Wm}{ }^{-1} \mathrm{~K}^{-1}\right)$ & 130 & 16.3 & 6.7 & 1.4 \\
Electrical conductivity $\left(\mathrm{MS} / \mathrm{m}^{2}\right)$ & 19.4 & 1.35 & 0.562 & $10^{-25}$ \\
Electrical resistivity $(\mu \Omega \mathrm{cm})$ & 5.15 & 74 & 178 & $10^{27}$ \\
\hline
\end{tabular}

dependent on the diameter of each wire and displayed in Table 3 below. The largest diameter wire will be considered in the following calculations due its capability of applying the greatest $F_{i n(S M A)}$ with a value of $2283 \mathrm{mN}$.

To calculate the required input force to grip an object, $F_{\text {in (grip) }}$, the values of the output gripping force, $F_{\text {out (grip })}$, as calculated in the previous section must be considered. Using these values of $F_{\text {out (grip) }}$ and Eq. 4, the value of $F_{\text {in(grip) }}$ for each object can be approximated, the results of which are presented in Table 4. It is also important to calculate the remaining force available from the SMA wire to close the jaws of the microgripper $\left(F_{\text {in }(\text { Jaw })}\right)$ using Eq. 14. Where $F_{i n(S M A)}$ is the maximum available force from the SMA wire $(2283 \mathrm{mN})$, the results are shown in Table 4.

$F_{\text {in }(\text { Jaw })}=F_{\text {in }(S M A)}-F_{\text {in }(\text { grip })}$

It was determined that the board connector requires the largest force to grip, while both wires require a much lower force. However, due to the size of the microgripper jaw, it requires a jaw tip displacement $\left(D_{\text {out }}\right)$ of $0.4 \mathrm{~mm}$ to grasp the board connector. The platinum wire and connector wire require a jaw tip displacement of $0.5 \mathrm{~mm}$ and $0.675 \mathrm{~mm}$ respectively. This is advantageous as the connector board requires the most energy to grip, but less energy is needed to displace the jaw tip. The wires on the other had will need a large input force to displace the jaw tips, but less force is required to grip each wire. When using Eq. 4 , the $F_{\text {out }}$

Table 3 The maximum pulling force available from Flexinol ${ }^{\circledR}$ SMA wires diameters $(\mathrm{mm})$ (DYNALLOY inc 2013)

\begin{tabular}{ll}
\hline Diameter $(\mathrm{mm})$ & $F_{\text {in }(\text { SMA })}(\mathrm{mN})$ \\
\hline 0.038 & 195.1 \\
0.05 & 337.7 \\
0.076 & 780.3 \\
0.1 & 1350.9 \\
0.13 & 2283
\end{tabular}

Table 4 Required force to grip each object $\left(F_{\text {out }(\text { grip }}\right)$ and the actuation force required $\left(F_{\text {in }(\text { grip })}\right)$ by the SMA and the remaining force available to close the microgripper jaw $\left(F_{\text {in }(J a w)}\right)$

\begin{tabular}{lccc}
\hline Objects & $F_{\text {out }(\text { grip })}(\mathrm{mN})$ & $F_{\text {in }(\text { grip })}(\mathrm{mN})$ & $F_{\text {in }(\text { Jaw })}(\mathrm{mN})$ \\
\hline Platinum wire & 87 & 174 & 2109 \\
Connector wire & 62 & 124 & 2159 \\
Connector board & 678 & 1356 & 927 \\
\hline
\end{tabular}

available to close the jaws of the microgripper was calculated to be $0.927 \mathrm{~N}$. It is this value of input force that will be used during the simulation experiments in the next section of this paper.

\section{Simulation}

To predict the gripping capability of the selected design, a finite element analysis (FEA) of the structure was conducted using the simulation software ANSYS 19.2. The main factors that were studied using this software were the $D_{\text {out }}$, displacement, stress, and thermal conductivity of the model. To conduct these tests, a model of the microgripper structure was created in SolidWorks software (Fig. 3). The 3D model was imported into ANSYS to simulate the impact of the microgripper structure and how it would act under temperature and force conditions. The model considered the three metal alloys (Table 2) and an elementmesh of the model was created and refined at the hinge sections to produce the most realistic representation and accurate results from the simulation. For each simulation, a predefined $F_{\text {in }}$ (Table 4 ) was applied at the input point on the microgripper body to represent the force of the SMA wire applied to the gripper to cause the jaw tips of the microgripper body to close $\left(D_{\text {out }}\right)$ the distance of $1 \mathrm{~mm}$. 


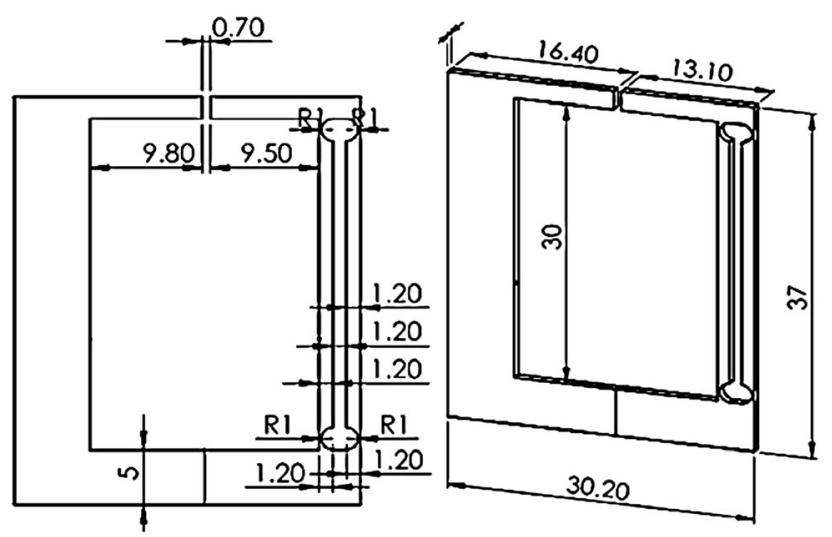

Fig. 3 Initial design of the microgripper structure

The first simulation to be conducted was to apply the specified input force to the microgripper and to define the simulated output displacement of the jaw tips. By completing this for each material, it would be possible to discover what maximum jaw tip displacement for each material would be obtained for the given input force. The second set of simulations to be completed involve studying the stress incurred by the structure. If the stresses of the structure exceed the linear elastic limit and enter the tensile yield limit of the material, the structure would no longer deform elastically and would permanently deform plastically and considered to have failed.

To ensure that the tensile yield limit is not reached during the actuating operation, these additional tests were conducted which simulated the maximum Von-Misses stress for each material structure whilst under the same predefined $F_{\text {in }}$ as the previous test. Following on from these tests, the dimensions of the microgripper were further studied to optimise its design. The radius and the bridge thickness of hinges on the flexible arm of the microgripper body were experimented to discover how they influenced the stress and deformation values of the structure. For these processes, the SMA wire could be disregarded. The aim is to achieve a larger output displacement by the jaw tips. The current limitation of this is the stresses that are experienced by the structure, specifically the hinges. A preliminary test was conducted to gain an understanding of how each variable impacted both the stress and the displacement of the structure. For the initial optimisation test, a range of values for the radius of the hinge were tested between $0.5 \mathrm{~mm}$ and $2.45 \mathrm{~mm}$. These values were selected to cover the ranges suggested by previous literature (Wang et al. 2013; Royson et al. 2015; Yang et al. 2017; Keoschkerjan and Wurmus 2002). Along with this, the hinge bridge thickness was set with constraints of 0.2 and 0.4. This lower constraint was obligatory to include due to the limitation of the proposed gripper fabrication method (wire $\mathrm{EDM}$ ). If the bridge has a thickness of less than $0.2 \mathrm{~mm}$, the risk of the bridge breaking during the fabrication process would be likely high. Additionally, the high limit restraint was added as a thickness greater than $0.4 \mathrm{~mm}$, which results in a much larger stress value and subsequently a very low deformation value. The $F_{\text {in }}$ of the microgripper was kept at a constant value of $0.927 \mathrm{~N}$ as this was the mathematical value calculated that the SMA wire is capable of supplying to the structure and material. All other dimensions were kept constant throughout the experiment. The screening optimisation method was selected for this initial test as this method is typically used to test a large array of values for given variables. The process generates quasi-random numbers between the stated upper and lower boundary values for each variable and tests the combinations in between. A set of 300 sample points were created by the ANSYS software with the above constraint included. The second optimisation test to be conducted is defined as the adaptive multiple-objective optimisation process. This process provides more refined results compared to the initial screening method of optimisation. Using the results from the previous experiment, the constraints of the variables were further refined.

\section{Results}

\subsection{Simulation results}

This section presents the results obtained for various tests conducted on different structure dimensions and material types using ANSYS FEA software. The main focus was on deformation of the structure during gripping, evidence of a $D_{\text {out }}$ of $1 \mathrm{~mm}$, and the stress at the hinge region (Fig. 4). The first material to be studied was the stainless steel 316 alloy. The results show that the jaw tip of the flexible arm of the structure produced a $D_{\text {out }}$ of $0.54 \mathrm{~mm}$ along the $\mathrm{z}$-axis. This shows that the stainless steel material is already an undesirable choice of material since it does not reach the required deformation of $1 \mathrm{~mm}$. The stress values experienced by the stainless steel 316 structure were examined next. As previously calculated, the available force from the SMA wire in order to close the microgripper had a value of $0.927 \mathrm{~N}$. The simulations showed that very little or no stress occurs across the majority of the microgripper body, and the only area of stress is at the hinge areas of the structure. These stresses exceeded the tensile yield limit of the stainless steel alloy resulting in a permanent deformation of the structure. To ensure that the stress of the stainless steel structure did not exceed its' tensile yield limit, the input force applied to the structure had to be reduced. It was found that an $F_{\text {in }}$ of $0.51 \mathrm{~N}$ was a suitable value to apply and resulted in a stress value of $290 \mathrm{MPa}$. Simulation of the gripper with this $F_{\text {in }}$ resulted in 
Fig. 4 a Displays the deformation of the Ti-6AI-4V structure whilst a maximum input force. b Fully closed gripper. c The stress points of the microgripper hinge region

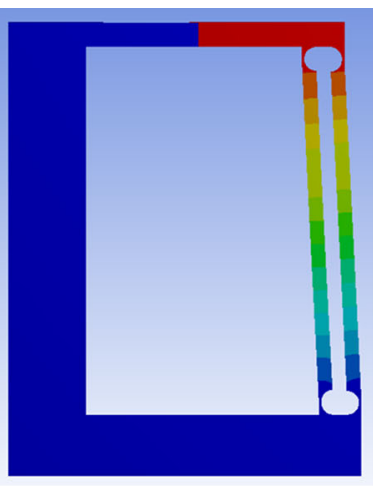

(a)

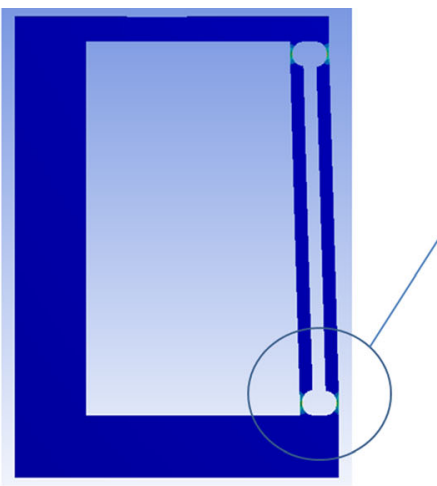

(b)

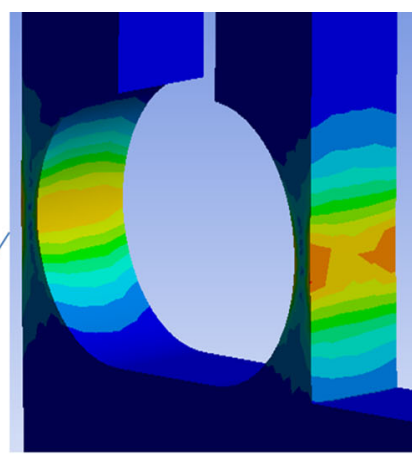

(c)

a $D_{\text {out }}$ of $0.303 \mathrm{~mm}$ at the jaws. This value is insufficient compared to the required displacement of $0.7 \mathrm{~mm}$, therefore it was deemed that the stainless steel alloy is an inadequate material for the selected design.

For the titanium alloy a $D_{\text {out }}$ of $0.91 \mathrm{~mm}$ was observed, which is higher than the required amount. Compared to the displacement of the stainless steel, this value was expected as the young's modulus of this metal is lower than that of the stainless steel, therefore a lower stiffness is experienced at each hinge. It was discovered that a maximum stress experienced at the hinges of the structure was $503 \mathrm{MPa}$ which is less than the tensile yield limit of the metal. The titanium alloy material structure has the potential of achieving a high $D_{\text {out }}$ of $1.4 \mathrm{~mm}$ before reaching its high tensile yield strength of $790 \mathrm{MPa}$, although a large $F_{\text {in }}$ of $(2.21 \mathrm{~N})$ would be required from the SMA wire to reach this value. To achieve the desired $D_{\text {out }}$ of $1 \mathrm{~mm}$, an $F_{\text {in }}$ of $1 \mathrm{~N}$ would be needed.

For the aluminium 7075-T6 the $D_{\text {out }}$ was measured as $1.45 \mathrm{~mm}$, which exceeds the required displacement. This is suitable as the $F_{\text {in }}$ can be reduced in order to achieve the correct displacement. The maximum stress of the structure reached $505 \mathrm{MPa}$, which is higher than the $434 \mathrm{MPa}$ tensile yield limit of the material. This shows that the maximum $F_{i}$ applied by the SMA wire would results in the structure is permanently deformed. To prevent this plastic deformation occurring, the $F_{\text {in }}$ value must be reduced to a value at which the tensile yield limit is reached. It was found that when the input force value was decreased to $0.791 \mathrm{~N}$, the stress value reached its maximum limit of $434 \mathrm{MPa}$. At this value the jaw tip $D_{\text {out }}$ was shown to be $1.25 \mathrm{~mm}$, which is sufficiently high enough for this operation. Since this value of stress is at the limit of the material's tensile yield stress, it would result in the microgripper to fail after multiple cycles. To prevent this, the $F_{i}$ value of the structure should be decreased.

For all three materials the maximum stress levels are located at the hinges of the structure (Fig. 4c). The hinges are the thinnest element of the structure, hence the lowest

cross-sectional area, and it is the hinges that must be observed to ensure that excessive stresses does not occur.

\subsection{Summary of stress and $\boldsymbol{F}_{i}$}

The stainless steel alloy had tensile yield values of $290 \mathrm{MPa}$. This value was reached whilst conducting the simulation test with an $F_{i}$ value of $0.53 \mathrm{~N}$. The aluminium alloy has a tensile yield limit of $434 \mathrm{MPa}$, which was also reached during tests with an $F_{i}$ value of $0.791 \mathrm{~N}$. Both of these materials reached their maximum stress limit during the test before the SMA wire was capable of applying its maximum potential force to these structures. However, the titanium alloy was capable of being deformed by the full potential force of the SMA wire of $0.927 \mathrm{~N}$ and reached a stress value of $503 \mathrm{MPa}$ out of a maximum of $790 \mathrm{MPa}$. This shows that this material would be capable of deforming a greater value if the applied $F_{i}$ value from the SMA wire was larger. These results suggest that for this particular design the stainless steel alloy may be an unsuitable choice of material to manufacture the microgripper body out of as it reached its plastic limit whilst being actuated by the SMA wire. This would result in the microgripper to become unusable and require to be replaced. It is also known that if the stress of the structure repeatedly reaches a value close to, but not reaching, the tensile yield limit, then the number of repetitive cycles that the microgripper can achieve will dramatically decreases.

\subsection{Summary of jaw displacement and $\boldsymbol{F}_{i}$}

The results of the $F_{i}$ value for each of the materials against the jaw $D_{\text {out }}$ (Fig. 5) are conducted within the linear elastic region of the stress-strain curve for each material as this is the area of interest for the experiment. The graph shows that as the $F_{i}$ value is increased, the $D_{\text {out }}$ value of the flexible jaw tip also increases in a linear fashion, revealing a directly proportional relationship. It is found that for the same applied force, each of the different materials 
Fig. 5 Input force applied by SMA wire actuator compared to the output displacement $(\mathrm{mm})$ of Aluminium 7075-TG,

Titanium 6AI-4V and Stainless steel 316

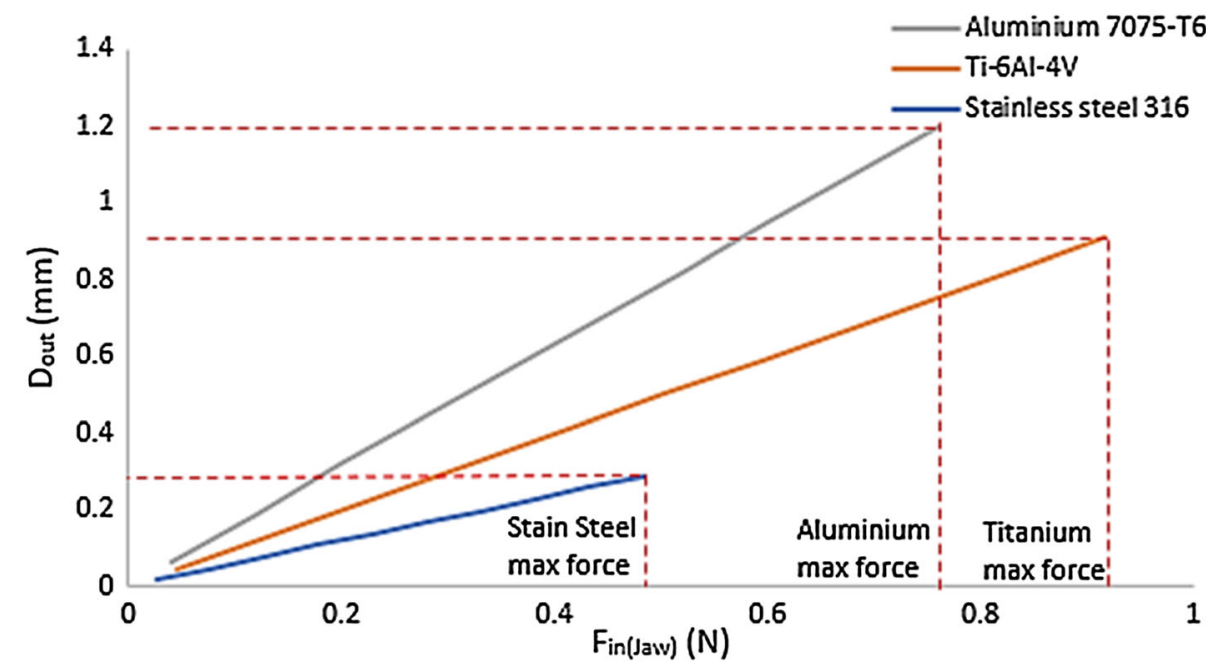

produces a vastly different value of $D_{\text {out }}$. The stainless steel alloy was only capable of reaching an $D_{\text {out }}$ value of $0.315 \mathrm{~mm}$, approximately half of the displacement value required, whilst at its maximum limit of $290 \mathrm{MPa}$. During practical use, the stress limit of the material should be reduced in order to ensure a high stress safety factor to prolong the microgripper lifespan, hence this final jaw displacement value will end up being less than the simulated value. This further suggests that the stainless steel alloy is an unsuitable choice of material to use for this microgripper body. The titanium alloy did not reach even two-thirds of its tensile yield stress (503 MPa). However, due to relatively high modulus of elasticity, this results in a stiffer structure that produced an $D_{\text {out }}$ value of $0.91 \mathrm{~mm}$. Of the three materials, the aluminium alloy has the largest modulus of elasticity and is capable of producing the largest $D_{\text {out }}$ value within its elastic region and with the $F_{i}$ applied from the SMA wire. Despite the aluminium alloy reaching its tensile yield limit in its initial test, this value was reached whilst the $D_{\text {out }}$ had reached $1.25 \mathrm{~mm}$, which is greater than the required value of $1 \mathrm{~mm}$. Therefore, this value is capable of being achieved without exceeding the materials' maximum stress value. It was identified that a displacement of $1 \mathrm{~mm}$ was achievable with a reasonable experienced stress value of $346 \mathrm{MPa}$. Using Eq. 13, the stress safety factor can be calculated as 1.25 . This shows that the structure is capable of experiencing 1.25 times the intended stress before plastic failure of the material will occur. The $F_{i}$ value required to attain the displacement of $1 \mathrm{~mm}$ was $0.63 \mathrm{~N}$, which is an acceptable value as it is less than the maximum force that the SMA wire is capable of producing. This reduced $F_{i}$ value will result in a longer lifespan of the wire. These findings suggest that the aluminium alloy is the most suitable material to fabricate the microgripper body.

\subsection{Thermal conductivity}

The simulation of thermal conductivity of the microgripper due to the SMA wire is required to be studied as the objects being handled by the microgripper are sensitive to heat. Temperatures up to the maximum input temperature $\left(T_{i}\right)$ that the SMA wire can reach of $80^{\circ} \mathrm{C}$ may occur. The thermal conductivity of the Aluminium 7075-T6 alloy was simulated and results show that $95 \%$ of the $T_{i}$ is conducted to the jaws and that the temperature at each jaw is different (Fig. 6). The results show that the majority of the heat conducted through the arms of the microgripper to the jaw tips, this is due to the high conductivity $\left(130 \mathrm{~W} \mathrm{~m}^{-1} \mathrm{~K}^{-1}\right.$ ) and the size of the structure. In order to reduce the thermal conductivity from the SMA wire, an additional simulation was conducted with a silicon rubber insulator placed

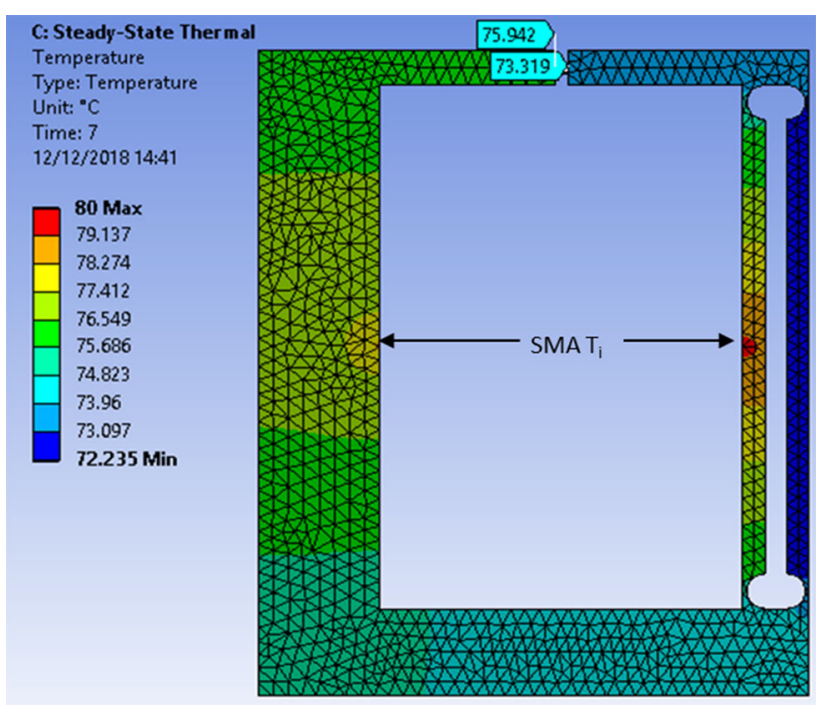

Fig. 6 Thermal conductivity test conducted on the aluminium 7075-T6 alloy microgripper body 
between the SMA wire and the input point of the microgripper body. The silicon rubber insulator has a thermal conductivity of $3 \mathrm{Wm}^{-1} \mathrm{~K}^{-1}$. The results of the test shows that the rubber insulator is capable of suppressing heat from the conducting SMA with only $35 \%$ of highest $T_{i}$ reaching the microgripper jaw tips (Fig. 7).

\section{Optimisation results}

Improvement and optimisation to shape and dimensions of the microgripper body was conducted on the aluminium 7075-T6 alloy in order to ensure maximum efficiency and the correct $D_{\text {out }}$ value achievement whilst reducing the stress on the structure. The optimisation process will consider an initial stage that modifies the hinge bridge thickness and radius dimensions. This is then followed by a second optimisation process to identify specific dimensions that maximise $D_{\text {out }}$ value whilst reducing structure stress.

\subsection{Hinge bridge optimisation of the aluminium 7075-T6 alloy}

The results in Fig. 8 display how the two dimensional variables impact the stress of the microgripper body. It can be seen that as the hinge bridge thickness and radius is increased, the stress of the structure decreases. Increasing the bridge thickness from 0.2 to $0.4 \mathrm{~mm}$ results in a stress reduction between 62.1 and $71.1 \%$. The hinge radius is less influential on the stress of the structure. When increasing the hinge radius from 0.5 to $2 \mathrm{~mm}$ the stress reduction is between 36.5 and $42.7 \%$. Figure 9 also shows that as the hinge bridge thickness is increased the $D_{\text {out }}$ value is decreased. However, as the hinge radius is increased, a large displacement of the jaw tip occurs. This results identify that a large radius would be the most preferable option whilst using small values for the hinge bridge thickness. However, there is no ideal combination of values for hinge bridge thickness and hinge radius this is because, as the stress of the structure decreases, the jaw $D_{\text {out }}$ value also decreases.

\subsection{Hinge bridge optimisation of the aluminium 7075-T6 alloy}

Based on the previous optimisation findings, the hinge radius was set to values between 1.8 and $2.25 \mathrm{~mm}$ as it was found that the data points between these values were capable of achieving the highest $D_{\text {out }}$. The dimensions of the hinge bridge thickness remained the same as in the previous test. The input force again remained at a constant value of $0.927 \mathrm{~N}$. From the collected results, the most optimum value of each variable was calculated. After comparing the data collected from the adaptive multiple-objective optimisation process, the most suitable dimensions of structure to be used is identified. The value for the radius was found to be $2.1 \mathrm{~mm}$ and hinge thickness was $0.279 \mathrm{~mm}$. Figure 10 shows the stress experienced by this design of microgripper is $219 \mathrm{MPa}$, which is sufficiently low enough compared to the tensile yield limit of the material of $434 \mathrm{MPa}$. The $D_{\text {out }}$ value of the optimised design can be seen in Fig. 11. The figure shows the displacement experienced by the microgripper is $0.717 \mathrm{~mm}$, which is slightly above the desired value of $0.7 \mathrm{~mm}$. The results in Fig. 12 show that the optimised microgripper dimensions are capable of producing the correct jaw displacement while limiting the stress incurred on the structure. Table 5 below shows the main specifications and the correct dimensions required to produce the microgripper using the WEDM manufacturing process.
Fig. 7 Results of thermal conductivity test conducted on the aluminium 7075-T6 alloy microgripper body with varying applied temperatures

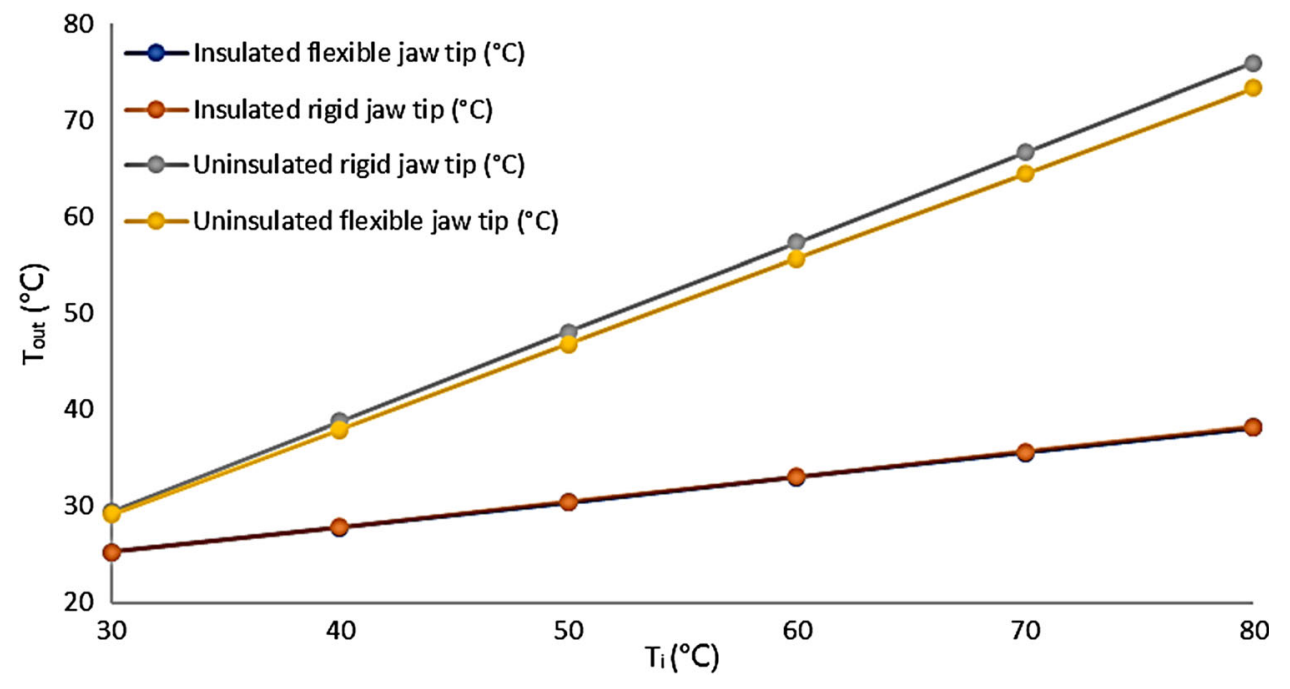


Fig. 8 Relationship between hinge bridge thickness, hinge radius and stress

Fig. 9 Relationship between hinge bridge thickness, hinge radius $D_{\text {out }}$

Fig. 10 Results from the second optimisation process displaying comparison between hinge bridge thickness and stress
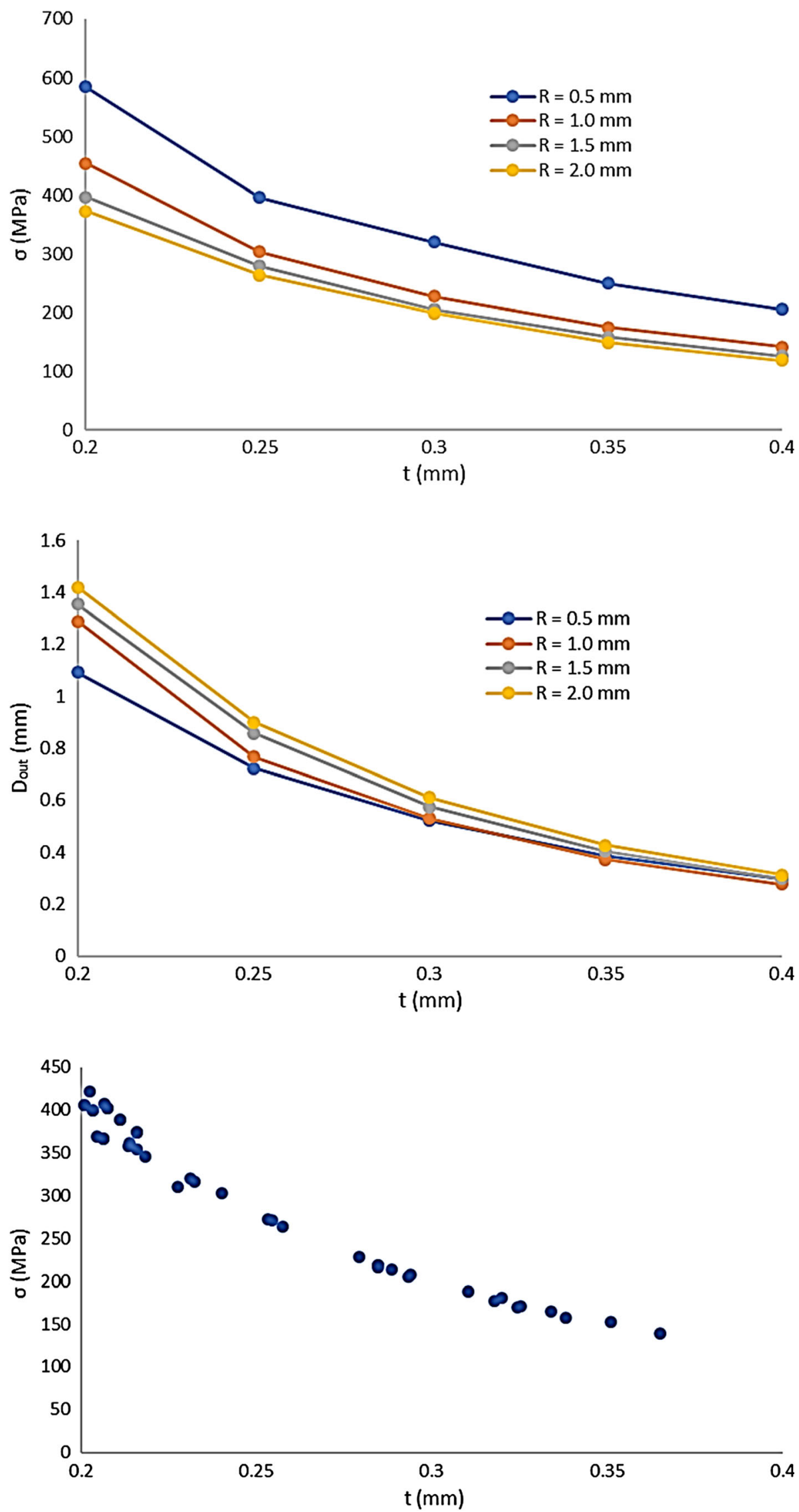
Fig. 11 Results from the second optimisation process displaying comparison between hinge bridge thickness and jaw tip displacement

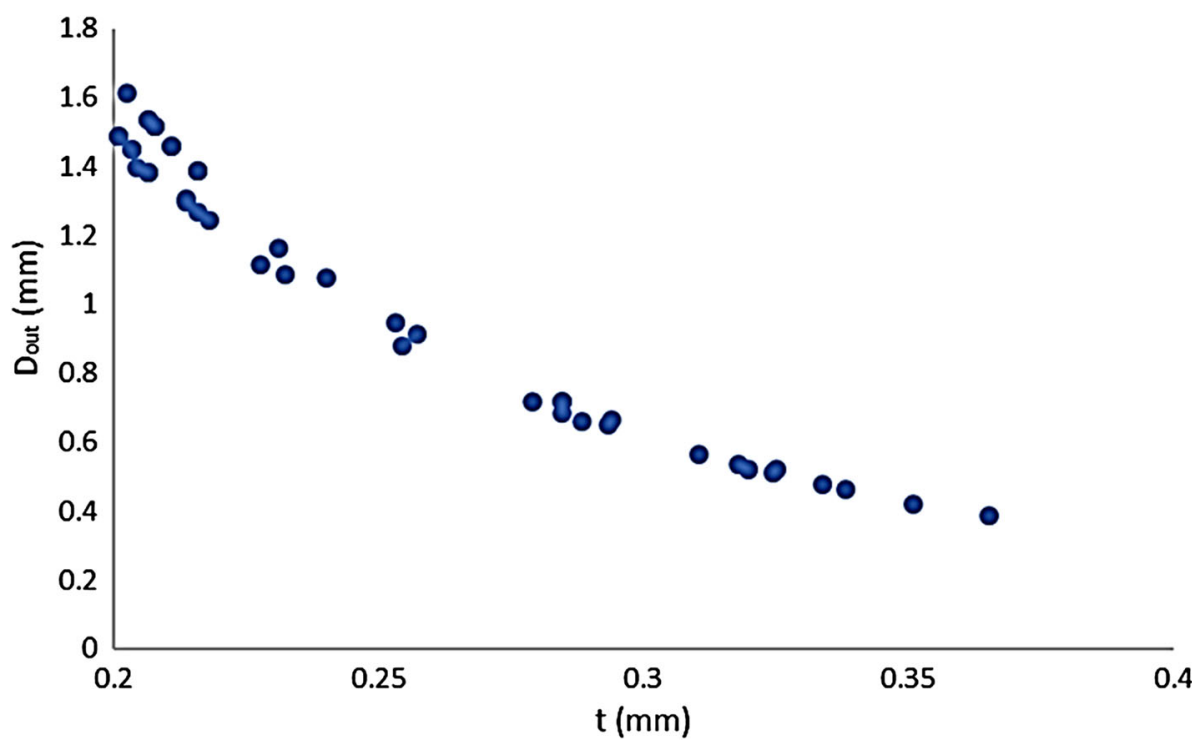

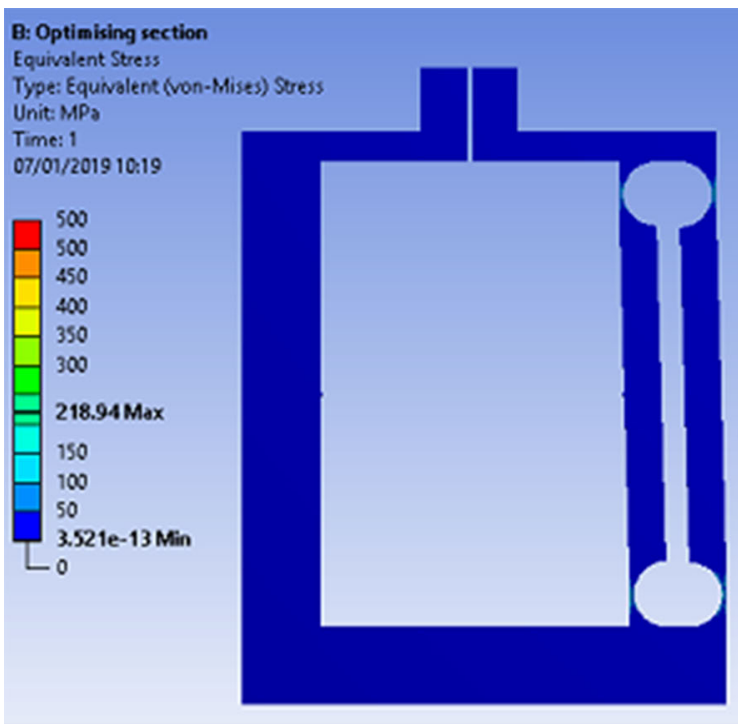

(a)

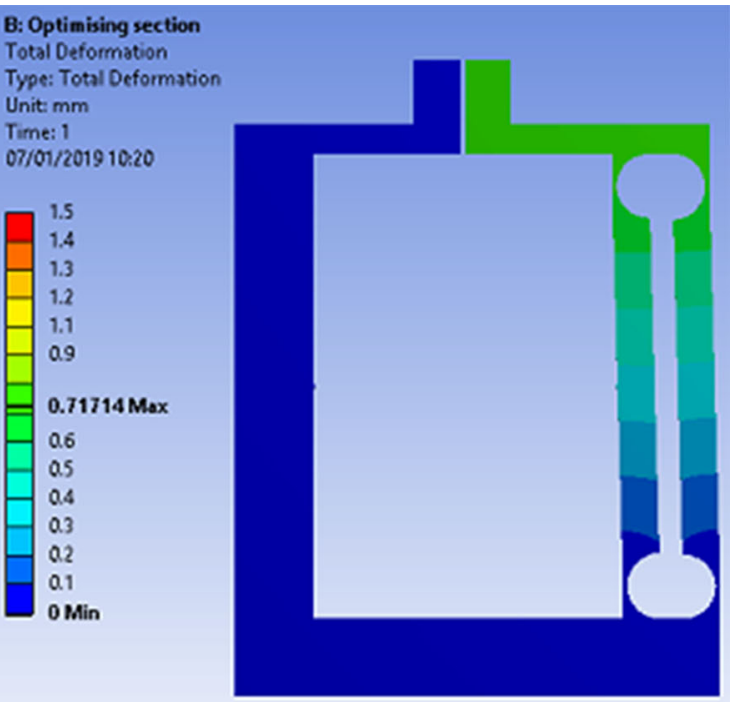

(b)

Fig. 12 Optimised dimensions of the aluminium 7075-T6 alloy microgripper with a hinge stress, $\mathbf{b}$ total deformation of the structure

Table 5 Optimised microgripper specifications

\begin{tabular}{lll}
\hline Variable name and symbol & \multicolumn{1}{c}{ Value } \\
\hline Body width & $w$ & $1 \mathrm{~mm}$ \\
Hinge thickness & $t$ & $0.279 \mathrm{~mm}$ \\
Radius of hinge & $R$ & $2.1 \mathrm{~mm}$ \\
Total length of microgripper arm & $l$ & $30 \mathrm{~mm}$ \\
Position of SMA wire up the arm & $d$ & $15 \mathrm{~mm}$ \\
Displacement output range & $D_{\text {out }}$ & $0.717 \mathrm{~mm}$ \\
SMA wire & Dynalloy's Ni-Ti Ø0.13 mm \\
Microgripper body material & Aluminium & $7075-\mathrm{T} 6$ alloy \\
\hline
\end{tabular}

\section{Conclusions}

The potential of microgrippers design and manufacturing to manipulate micro-sized components has been demonstrated. The investigated microgripper considered a parallelogram flexible hinge design, three gripper materials and a novel actuation system using SMA for the grasping of three different size components. The research considered the actuation forces required and the environment in which the device operates. An FEA analysis of the microgripper structure studied the jaw displacement, stress on the gripper, and the thermal behaviour from the actuator. The design is a first in that it incorporates an SMA actuator 
along with a single fixed and single flexible gripping arm to ensure a consistent datum point that is capable of gripping a $25 \mu \mathrm{m}$ platinum wire, a $0.2 \mathrm{~mm}$ connector wire, and a $0.3 \mathrm{~mm}$ thick printed circuit board connector. The main finding are as follows.

- The final closing position and the location of the object are required to be highly accurate to avoid inaccuracies during assembly. A parallelogram structure that includes flexible single-notch hinges was identified as a design start point. A study of the forces of this one degree of freedom structure identified the required displacement values to grip the selected components.

- To achieve a high displacement value for the microgripper, various materials have been studied. The design required high physical flexibility of the structure to allow for high displacement values while also having a tensile yield limit that is high enough so that actuation did not exceed this elastic limit of the main body. The aluminium alloy 7075-T6 was identified as the optimum material for achieving high displacement values and withstand the stress. However, the thermal conductivity of this material was shown to be disadvantageous as it would be capable of conducting the electrical current and heat from the SMA wire.

- The simulation results that focused on the stress of the microgripper body during actuation for the three different materials showed that the steel and aluminium materials reached their maximum stress limit during the test before the SMA wire was capable of applying its maximum potential force to these structures. The titanium alloy was capable of being deformed by the full potential force of the SMA wire below its tensile limit. For all three materials the maximum stress levels are located at the hinges of the structure.

- The results of the $F_{\text {in }}$ value for each material against the jaw $D_{\text {out }}$ are presented. The results showed that as the $F_{\text {in }}$ value is increased, the $D_{\text {out }}$ value of the flexible jaw tip also increases in a linear fashion, revealing a directly proportional relationship. The stainless steel alloy was not capable of reaching the displacement value required making it an unsuitable choice to be used for this microgripper design. The aluminium alloy has the largest modulus of elasticity and is capable of producing the largest $D_{\text {out }}$ value with the $F_{\text {in }}$ applied from the SMA wire. Despite the aluminium alloy reaching its tensile yield limit in its initial test, it is shown that by reducing the $F_{\text {in }}$ applied, the materials' maximum stress value is not exceeded.

- Due to the temperature sensitivity of some components, the simulation of thermal conductivity of the microgripper due to the SMA wire is required. The temperature that the SMA wire can reach is $80^{\circ} \mathrm{C}$ and it can be seen that for the three materials studied up to $95 \%$ of the generated heat was conducted to the jaws. For temperature sensitive assembly, the application of an insulation material was shown to be effective in reducing this effect, and should be a consideration when designing the gripper.

- Further design optimisation of the hinge dimensions was also conducted to improve the operation of the gripper. The findings showed that there is no ideal combination of values for hinge bridge thickness and hinge radius. This is because, as the stress of the structure decreases, the jaw tip displacement also decreases. To produce a larger jaw tip displacement, the bridge thickness must be decreased and the radius must be increased. Based on these observations, a screening optimisation method and an adaptive multiple-objective optimisation process were used to find the most suitable dimensions of the structure. The results identified the optimum microgripper dimensions for the identified tasks.

Acknowledgements The authors would like to acknowledge the support of the Advanced Sustainable Manufacturing Technologies (ASTUTE 2022) project, which is partly funded from the EU's European Regional Development Fund through the Welsh European Funding Office, in enabling the research upon which this paper is based. Further information on ASTUTE can be found at www. astutewales.com.

Open Access This article is distributed under the terms of the Creative Commons Attribution 4.0 International License (http://creative commons.org/licenses/by/4.0/), which permits unrestricted use, distribution, and reproduction in any medium, provided you give appropriate credit to the original author(s) and the source, provide a link to the Creative Commons license, and indicate if changes were made.

\section{References}

Adriaens HJMTA, De Koning WL, Banning R (2000) Modeling piezoelectric actuators. IEEE/ASME Trans Mechatron 5(4):331-341

ASM International (1990) Handbook committee, Properties and selection: nonferrous alloys and special-purpose materials. Volume 2 of Metals handbook properties and selection: nonferrous alloys and special- purpose materials, 10th edn. ASM International, New York

ASTM International (1994) Standard specification for tin-coated soft or annealed copper wire for electrical purposes, West Conshohocken

Chen T, Chen L, Sun L, Li X (2009) Design and fabrication of a fourarm-structure MEMS gripper. IEEE Trans Ind Electron 56(4):996-1004

Chronis N, Chronis N, Lee LP (2005) Electrothermally activated SU8 microgripper for single cell manipulation in solution electrothermally activated SU-8 microgripper for single cell manipulation in solution. Microelectromech Syst 14(August):857-863 
Chu Duc T, Creemer JF, Sarro PM (2006) Lateral nano-Newton force-sensing piezoresistive cantilever for microparticle handling. J Micromech Microeng 16(6):102-106

Chun JKR, Ernst S, Matthews S, Schmidt B, Bansch D, Boczor S, Ujeyl A, Antz M, Ouyang F, Kuck KH (2007) Remotecontrolled catheter ablation of accessory pathways: results from the magnetic laboratory. Eur Heart J 28(2):190-195

Dumetz E, Dieulot J-Y, Barre P-J, Colas F, Delplace T (2006) Control of an industrial robot using acceleration feedback. J Intell Robot Syst 46(2):111-128

DYNALLOY inc. (2013) Technical characteristics of FLEXINOL ${ }^{\circledR}$, pp $1-12$

Festo (2006) Parallel grippers HGPT, HGPL and three-point grippers HGDT. https://www.festo.com/net/SupportPortal/Files/26915/ info_139_en.pdf

Gaafar E, Zarog M (2017) A low-stress and low temperature gradient microgripper for biomedical applications. Microsyst Technol 23(12):5415-5422

Howell LL, Magleby SP, Olsen BM (2013) Handbook of compliant mechanisms. Wiley, Hoboken

Keoschkerjan R, Wurmus H (2002) A novel microgripper with parallel movement of gripping arms. In: Proceedings of 8th international conference on new actuators, no 1, pp 321-324

Kolahdoozan M, Esfahani AR, Hassani M (2017) Experimental and numerical investigation of the arms displacement in a new electrothermal MEMS actuator. Int J Adv Des Manuf Technol 10(2):71-81

Kyung JH, Ko BG, Ha YH, Chung GJ (2008) Design of a microgripper for micromanipulation of microcomponents using SMA wires and flexible hinges. Sens Actuators, A Phys 141(1):144-150

Liang C, Wang F, Shi B, Huo Z, Zhou K, Tian Y, Zhang D (2018) Design and control of a novel asymmetrical piezoelectric actuated microgripper for micromanipulation. Sens Actuators, A Phys 269:227-237

Lin CM, Fan CH, Lan CC (2009) A shape memory alloy actuated microgripper with wide handling ranges. In: IEEE/ASME international conference on advanced intelligent mechatronics. AIM, pp 12-17

Long Z, Zhang J, Liu Y, Han C, Li Y, Li Z (2017) Dynamics modeling and residual vibration control of a piezoelectric gripper during wire bonding. IEEE Trans Compon Packag Manuf Technol 7(12):2045-2056

Munasinghe KC, Bowatta BGCT, Abayarathne HYR, Kumararathna $\mathrm{N}$, Maduwantha LKAH, Arachchige NMP, Amarasinghe YWR (2016) New MEMS based micro gripper using SMA for micro level object manipulation and assembling. In: 2nd international Moratuwa engineering research conference, MERCon 2016, pp 36-41
Nah SK, Zhong ZW (2007) A microgripper using piezoelectric actuation for micro-object manipulation. Sens Actuators, A Phys 133(1):218-224

Nikoobin A, Hassani Niaki M (2012) Deriving and analyzing the effective parameters in microgrippers performance. Sci Iran 19(6): 1554-1563

Royson D, Kumar S, Karanth N (2015) Design, modeling and simulation of a 2-DOF microgripper using piezoelectric actuator. STM 2(1):10-18

Shi Q, Yu Z, Wang H, Sun T, Huang Q, Fukuda T (2018) Development of a highly compact microgripper capable of online calibration for multi-sized microobject manipulation. IEEE Trans Nanotechnol 17(4):657-661

Smith ST, Chetwynd DG (2005) Foundations of ultra-precision mechanism design. Gordon and Breach Science Publishers, London

Wang DH, Yang Q, Dong HM (2013) A monolithic compliant piezoelectric-driven microgripper: design, modeling, and testing. IEEE/ASME Trans Mechatron 18(1):138-147

Wang F, Liang C, Tian Y, Zhao X, Zhang D (2015) Design of a piezoelectric-actuated microgripper with a three-stage flexurebased amplification. IEEE/ASME Trans Mechatron 20(5):2205-2213

Xiao S, Li Y, Zhao X (2011) Optimal design of a novel micro-gripper with completely parallel movement of gripping arms. In: IEEE International Conference on Robotics, Automation and Mechatronics, RAM-proceedings, pp 35-40

$\mathrm{Xu}$ Q (2018) Design, modeling, and control of a constant-force microgripper. Micromachines for biological micromanipulation. Springer, Cham, pp 119-143

Yang S, Xu Q (2017) A review on actuation and sensing techniques for MEMS-based microgrippers. J Micro-Bio Robot 13(1-4):1-14

Yang YL, Wei YD, Lou JQ, Fu L, Fang S (2017) Design and control of a multi-DOF micromanipulator dedicated to multiscale micromanipulation. Smart Mater Struct 26(11):115016

Yuan G, Yuan W, Hao Y, Li X, Chang H (2015) A microgripper with a post-assembly self-locking mechanism. Sensors (Switzerland) 15(8):20140-20151

Zhong ZW, Yeong CK (2006) Development of a gripper using SMA wire. Sens Actuators, A Phys 126(2):375-381

Zubir MNM, Shirinzadeh B, Tian Y (2009) Development of a novel flexure-based microgripper for high precision micro-object manipulation. Sens Actuators, A Phys. 150(2):257-266

Publisher's Note Springer Nature remains neutral with regard to jurisdictional claims in published maps and institutional affiliations. 